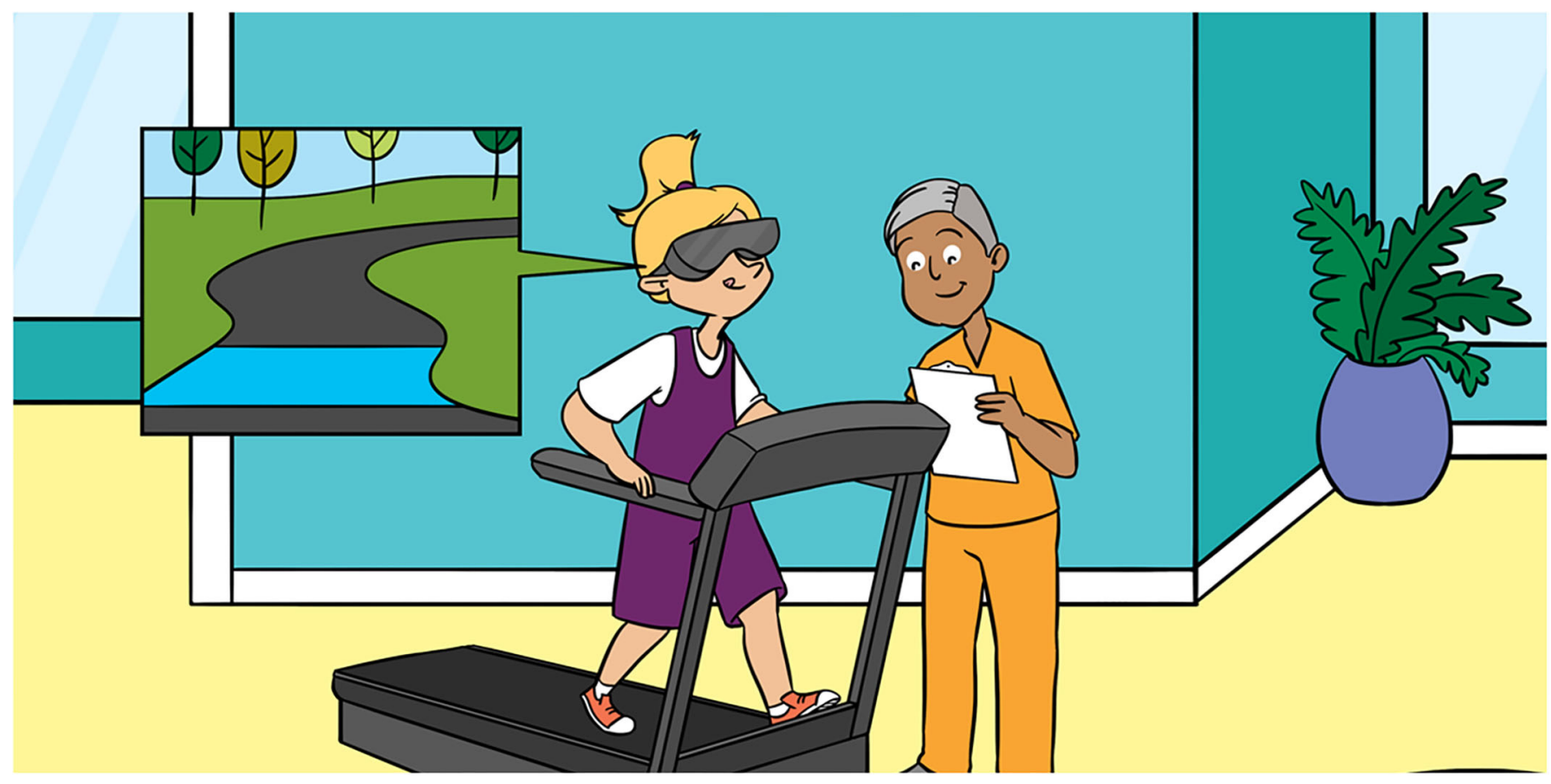

\title{
LEVELING UP INJURY RECOVERY: VIDEO GAMES FOR GOOD!
}

\section{Sean Cochran ${ }^{1}$ and Michael C. Hout ${ }^{2,3^{*}}$}

${ }^{1}$ Motor Behavior and Sport Psychology Laboratory, Department of Kinesiology and Dance, New Mexico State University, Las Cruces, NM, United States

${ }^{2}$ Vision Sciences and Memory Laboratory, Department of Psychology, New Mexico State University, Las Cruces, NM, United States

${ }^{3}$ Addison Care Virtual Reality and Augmented Reality Laboratory, New Mexico State University, Las Cruces, NM, United States

YOUNG REVIEWERS:

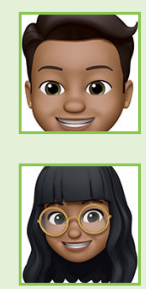

NAVIN

AGE: 13

RANJANA

AGE: 15
Have you ever heard that video games are not good for you, or that playing them is simply a waste of time? It is a common misconception that video games only provide entertainment and hold little or no other value. One important piece of technology can provide entertainment, can be used in educational settings, and is now even being incorporated into medical practice: virtual reality. Virtual reality refers to computer-generated reality that is in some ways similar to the reality we experience every day. This virtual world is used to "trick" our brains into feeling like we are somewhere else [1], but importantly, doctors are now also using VR as a tool to help people with mobility problems. Imagine injuring your foot or leg so badly that you are unable to walk properly. Now imagine getting better through the use of VR! 


\section{VIRTUAL REALITY}

Computer-generated representation of an environment that can be interacted with in a realistic way using equipment, such as a headset and controllers

\section{OPTIC FLOW}

The apparent motion of objects in a visual scene caused by the relative motion between an observer and the environment.

\section{VIRTUAL REALITY－NOT JUST FOR VIDEO GAMES!}

Virtual reality $(V R)$ is a computer-generated reality that is in some ways similar to the reality we experience every day and has made a large impression on the video game industry. Many people think that VR is simply a technology used for entertainment. But recently, VR has proven to be useful in the medical field. How? Well, have you ever injured your leg or foot such that you were unable to walk normally? It turns out that VR is a good tool for walking practice following an injury! VR can be adjusted to fit the training needs of the patient by creating a virtual scenario like walking through a busy park, but in a safe, real-world environment like the doctor's office.

Typically, when you play video games you see them on a screen in front of you. VR allows users to take a step "into" that screen and be "inside" the world of the game. This allows users to see the virtual world around them and interact with objects much like they would in the real world. People who have trouble walking due to injuries need to practice walking in a safe environment, because they have a high risk of falling and reinjuring themselves. VR makes this possible because patients can practice walking in what feels like a "real" environment, while remaining in the safety of their doctor's office.

VR systems used for helping people to walk again have additional safety features. For example, in some setups, the person exploring the virtual world may be strapped into a safety harness to help him or her maintain a constant upright position, which lowers the chances of the person being hurt. In other scenarios, the person exploring the virtual world may be supported by a trained physical therapist who ensures that the patient does not trip or lose balance (Figure 1). With the added safety and mobility that such VR setups provide, there are now many possibilities and practical uses for VR in physical rehabilitation.

\section{VR TRAINING FEELS REALISTIC}

For VR to be enjoyable and effective, it must feel life-like to the person using it. Different design features are incorporated into VR to make it seem realistic to the user. Virtual environments for practicing walking must have an obvious path for the person to walk along and should engage as many senses as possible. Imagine wearing a VR headset and seeing a path through a park in front of you. As you step, you can feel your feet moving and pushing against the surface you are standing on. You may also be able to hear the birds chirping and see different objects in the park as you walk forward.

Now, imagine you are walking along this virtual path and the park bench beside you moves along with you. This would feel strange, right? This illustrates a necessary characteristic of VR called optic flow. Optic flow in a virtual environment is important for making you feel 
Figure 1

A virtual reality set up used for walking practice. In this example, a physical therapist provides support to a young patient as he walks on the treadmill and steps over virtual obstacles presented to him in the headset.

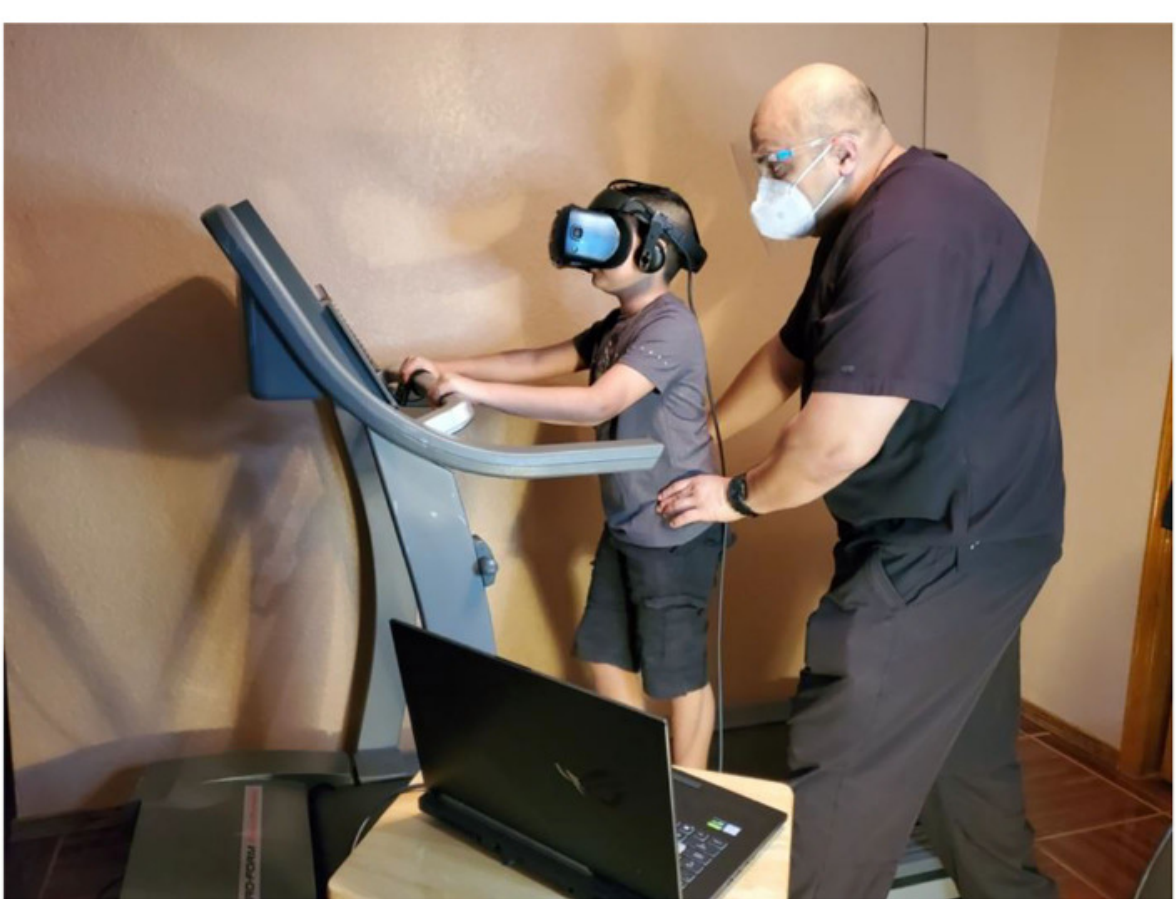

Figure 1

like you are moving through an environment the way you would in the real world. For example, as you are walking forward in this simulated park, the bench should be moving away from you once you pass it. Optic flow allows users to perceive themselves as moving forward in the virtual world, even though they may in fact just be walking in place on a treadmill!

With these important characteristics of the environment in place, VR can be an extremely helpful tool for injury recovery, for two main reasons. First, VR helps make the training exercises feel more like what patients would experience when walking in the real world. In the absence of VR, a doctor might ask a patient to walk on a treadmill while looking in the mirror. But does this seem like something a patient would do outside of the office? Of course not. This is where VR can help to make movement practices seem more like what a patient might do outside of the doctor's office. Second, think about what you would enjoy more. Would you prefer to watch yourself in the mirror as you walk, or would you prefer to be walking through a virtual park, where you can observe and maybe even interact with items in your environment? VR not only creates an environment similar to what patients would experience outside of the office, but will also keep them interested in coming back to the doctor, creating more "buy-in," or willingness to actively participate in their rehabilitation exercises [2]. 
Figure 2

A VR obstacle-crossing training session that might be performed in a doctor's office. The blue line represents an obstacle in the patient's path that must be stepped over. In VR, the user often cannot see his or her own body, so patients may instead see markers like these blue and white objects (right) that tell them where their feet are at all times.
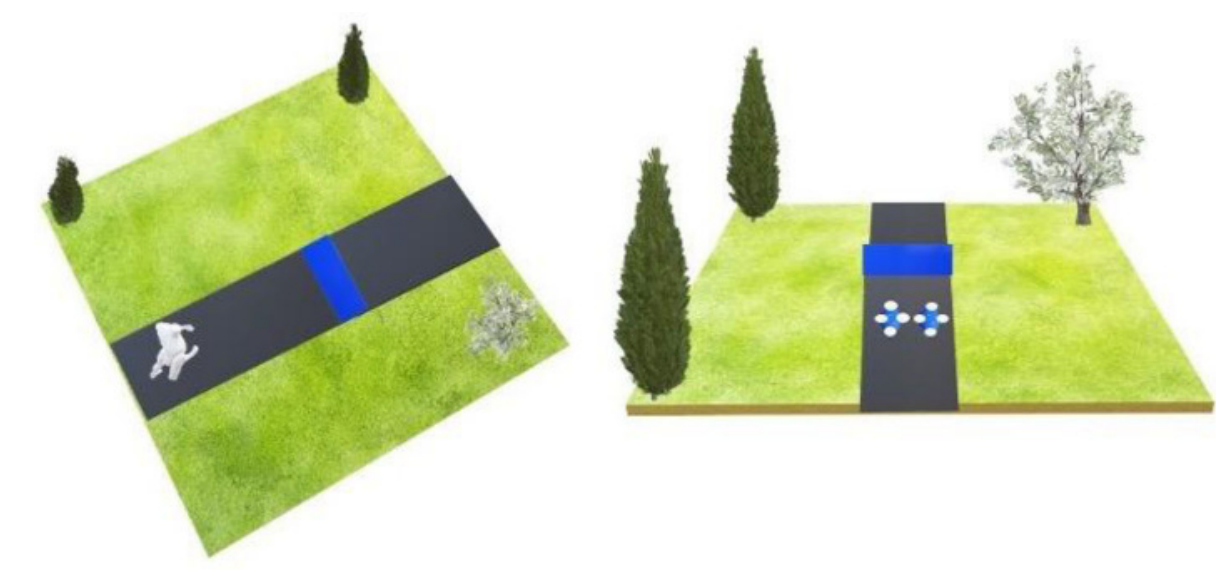

Figure 2

\section{EXAMPLES OF VIRTUAL WALKING PRACTICE}

There are multiple ways to help a person walk better using VR. One form of practice consists of navigating obstacles in a multi-sensory game-like situation. This training typically puts the patient in a virtual environment similar to a situation they would be required to walk through in real life, such as walking through a crowded park or attempting to cross a busy street. Objects are placed in the person's way to disrupt their path, so rather than walking in a simple and repetitive straight line, the virtual world engages the person's attention and activates other muscle groups that are used for balance when navigating obstacles. For example, imagine someone left toys scattered across the floor of your house. You want to get to the other side of the room without stepping on and breaking the toys, so you must zigzag to cross the room, or step over the toys as you get close to them. This means you must use different muscles and step lengths to make it to the other side safely. A randomized pattern of objects placed in a person's path also promotes learning, helping the patient to prepare for the unpredictable nature of a typical real-world environment [3].

So, what might walking practice look like in VR? Using the previous example, a VR environment like the one shown in Figure 2 could be used. Patients would be on a treadmill, in the safe environment of the doctor's office, so they would be able to walk through the simulated world with minimal risk of injury. Doctors can put virtual obstacles in the way (represented by the blue bar), which the patients must try to step over as they virtually approach them. One potential concern in VR is that the user can see what is presented in the headset but usually cannot see their own body. So, while patients are stepping over the obstacles, they might also be able to see a representation of their feet (the blue objects with white circles) so they can accurately plan their movements. 


\section{FEEDBACK}

Information given to patients showing them how well they did at completing a task. This information helps them improve the next time they complete the same task.

KNOWLEDGE OF PERFORMANCE

A feedback process in which a person is told how well they are doing at a task while performing the task.

\section{KNOWLEDGE OF} RESULTS

A feedback process in which a person is told how well they performed the task after the task was completed.
The virtual system typically gives feedback to let patients know if they were able to step over the obstacle successfully. One possible way to provide such feedback is by turning a virtual foot one color (say, green) when the patient steps over the obstacle successfully and another color (red) when the patient bumps into the object. Bear in mind, because it is virtual, even if the patients "bump into" something, it would not interfere with the motion of their feet and therefore it would not trip them! This feedback process is known as knowledge of performance, and it allows patients to know how well they are performing as they train, so that they can try to improve their movements when the next obstacle is encountered.

Importantly, not only can patients receive feedback during their movements, but they can also receive feedback afterwards regarding their overall performance. This is known as knowledge of results. This feedback is typically provided using an overall percentage score, like a grade on an exam. Current research is investigating whether knowledge of performance or knowledge of results is more beneficial, but combining the two can provide a complete picture of a patient's performance. By doing this, the doctor can figure out whether a patient is getting better over time, and thus, whether the treatment is working.

\section{VR TRAINING HELPS WITH REAL-LIFE SITUATIONS}

Research has shown that people improve how well they navigate real-world environments after VR training. One research group used VR training to present obstacles to participants as they walked in a straight line [4]. The objective was to avoid the obstacles as best they could. Performers then got a score showing how well they did at the end of each practice. After completing the VR practices, they were instructed to walk over similar obstacles in the real world. People who practiced walking over obstacles in VR were able to cross over real-world obstacles better than they could before training. These improvements show that what people learn in VR transfers to a real-world environment, improving real-world walking performance in important ways.

If researchers can see these improvements in a person's walking strategy based on virtual training, there may be endless possibilities for improvements in other human movements, such as skills involving manipulating an object (like cutting vegetables with a knife) or upper body mobility (like putting away groceries). This is an exciting new research area in rehabilitative medicine. Currently, more investigation is needed to see if virtual training improves physical movements other than just walking, but physicians and researchers are hopeful. 


\section{CONCLUSION}

Virtual reality is useful for more than just video game entertainment. Through VR, doctors can help people rehabilitating from physical injury to practice physical movements in an environment that is safe, but that also presents challenges that are similar to those in the real world. The multisensory "game-like" characteristics and feedback processes that VR offers help patients to feel more involved in their walking training. This combined immersion, mobility, and safety make VR an excellent option for the rehabilitation of injuries that impair normal walking. In the past, a VR system used for this kind of training consisted of a wired headset, controllers, a desktop computer, and sometimes safety measures like harnesses. But today, many VR systems are transitioning to portable and wireless technologies. With these updates to VR technology, patients may even be able to recover by using their own VR technology at home! Hopefully, in the near future, VR will help rehabilitate people experiencing other motor problems, too.

\section{REFERENCES}

1. Penn, R., and Hout, M. C. 2018. Making reality virtual: how VR "tricks" your brain. Front. Young Minds 6:62. doi: 10.3389/frym.2018.00062

2. Lohse, K., Shirzad, N., Verster, A., Hodges, N., and Van der Loos, H. M. 2013. Video games and rehabilitation: using design principles to enhance engagement in physical therapy. J. Neurol. Phys. Ther. 37:166-75. doi: 10.1097/NPT.00000 00000000017

3. Shea, J., and Morgan, R. 1979. Contextual interference effects on the acquisition, retention, and transfer of a motor skill. J. Exp. Psychol. Hum. Learn. Mem. 5:179-87. doi: 10.1037/0278-7393.5.2.179

4. LoJacono, C. T., Raisbeck, L. D., Ross, S. E., Rhea, C. K., MacPherson, R. P., and Kuznetsov, N. A. 2018. Obstacle crossing in a virtual environment transfers to a real environment. J. Motor Learn. Dev. 6:234-49. doi: 10.1123/jmld.2017-0019

SUBMITTED: 08 June 2020; ACCEPTED: 18 February 2021;

PUBLISHED ONLINE: 17 March 2021.

EDITED BY: Laura Ferraro, University of Palermo, Italy

CITATION: Cochran S and Hout MC (2021) Leveling Up Injury Recovery: Video Games for Good! Front. Young Minds 9:552774. doi: 10.3389/frym.2021.552774

CONFLICT OF INTEREST: The authors declare that the research was conducted in the absence of any commercial or financial relationships that could be construed as a potential conflict of interest.

COPYRIGHT (c) 2021 Cochran and Hout. This is an open-access article distributed under the terms of the Creative Commons Attribution License (CC BY). The use, distribution or reproduction in other forums is permitted, provided the original 

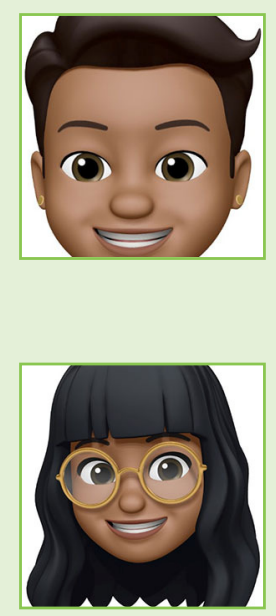

author(s) and the copyright owner(s) are credited and that the original publication in this journal is cited, in accordance with accepted academic practice. No use, distribution or reproduction is permitted which does not comply with these terms.

\section{YOUNG REVIEWERS}

\section{NAVIN, AGE: 13}

I am interested in the medical field and aspire to become an anesthesiologist in the future. I enjoy reading and drawing cartoons. I have been playing ice hockey and love being on the rink. Tennis, swimming, and cross-country are my favorite sports. I love eating anything that is vegetarian. I want to contribute to my community in any way I can and make a positive change.

\section{RANJANA, AGE: 15}

I love science and am especially into medicine. I am passionate about health and wellness. I enjoy reading and watching heist movies. I love spending time in labs, researching, and learning. I would like to learn more languages; right now, I can speak three. I hope to travel to more countries in the future!

\section{AUTHORS}

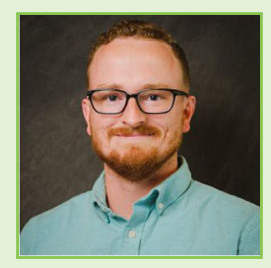

\section{SEAN COCHRAN}

Sean M. Cochran is a Ph.D. student in the department of Kinesiology and Dance with an emphasis in motor control and learning. His primary research interests are the effects of virtual reality training on motor skill transfer and cognitive performance. He received his M.S. in Applied Neuromechanics as well as his B.S. in Sport Medicine from the University of North Carolina at Greensboro.

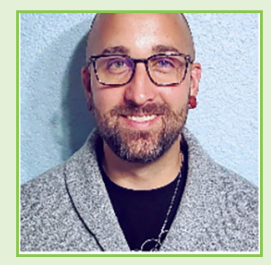

\section{MICHAEL C. HOUT}

Michael C. Hout is an Associate Professor in the Department of Psychology at New Mexico State University, and a Program Director at the National Science Foundation. His research focuses primarily on visual cognition (including search, attention, eye movements, and memory) and the development of methods of collecting similarity data for use in multi-dimensional scaling. He has won several awards for research and teaching, including the Rising Star award from the Association for Psychological Science. In his limited free time, he enjoys walking his dog, running, hiking, and playing hockey. *mhout@inmsu.edu 